\title{
Diminutif Poliplerin Endoskopik Tedavisinde Jumbo Forseps ve Soğuk Snare ile Polipektomi Yöntemlerinin Karșılaștırılması
}

\section{Jumbo Forceps Polypectomy Versus Cold Snare Polypectomy for Removal of Diminutif Colorectal Polyps}

\author{
${ }^{1}$ Mukaddes TOZLU \\ ${ }^{1}$ Sakarya Üniversitesi Tıp Fakültesi Gastroenteroloji Bölümü, Sakarya, Türkiye
}

Mukaddes Tozlu: https://orcid.org/0000-0002-8534-8027

\section{ÖZ}

Amaç: Kolonoskopi sırasında bulunan poliplerin çoğu 5 mm'nin altındadır. Polipektomi teknikleri endoskopistler arasında çok değişkendir ve endoskopistin tercihine göre belirlenmektedir. Bu çalıșmada diminutif polip (DP) olarak adlandırılan, $\leq 5 \mathrm{~mm}$ poliplerde, jumbo forseps (JFP) ve soğuk snare (CSP) ile yapılan polipektomilerin tam rezeksiyon oranları ve komplikasyonlar yönünden karş1laştırılması amaçlanmıştır.

Materyal ve Metot: Kliniğimizde herhangi bir nedenle kolonoskopi yapilan ve $\leq 5 \mathrm{~mm}$ polip saptanan hastalar; JFP ve CSP grubu olarak iki gruba randomize edildi. Polipektomi yöntemleri komplikasyon ve rezeksiyon açısından karşılaștırıldi.

Bulgular: Toplam 100 polipektomi işlemi (JFP grubu $=50$ ve CSP grubu=50) analiz edildi. Ortalama hasta yaşı $59,1 \pm 11,2$ yıldı ve 54 'ü $(\% 54)$ erkekti. Hastaların demografik özellikleri ve polip karakteristikleri gruplar arasında benzerdi. DP'ler için genel tam rezeksiyon oranı, JFP ve CSP grupları arasında önemli ölçüde farklı değildi (\%90'a karș $\% 82, \mathrm{P}=0,38)$. $\leq 3 \mathrm{~mm}$ poliplerde polipektomi süresi CSP grubunda anlamlı olarak uzundu $(\mathrm{p}=0,008)$ CSP grubunda \%4 minör kanama izlendi ve 4 polip (\%8) çıartılamadı. Komplikasyon oranı CSP grubunda anlamlı olarak yüksek saptand $(\mathrm{p}=0,01)$.

Sonuç: $\leq 5 \mathrm{~mm}$ kolorektal poliplerin eksizyonunda, rezidü açısından JFP ve CSP yöntemlerinin birbirlerine üstünlük sağladıkları gösterilmemiştir, ancak JFP yöntemi ile komplikasyon oranları daha düşük saptanmıștır.

Anahtar Kelimeler: Biyopsi, forseps, kolon polipleri, kolonoskopi

\section{ABSTRACT}

Objective: Most polyps found during colonoscopy are diminutive $(\leq 5 \mathrm{~mm})$. Polypectomy techniques are highly variable and determined by the endoscopist's preference. The aim of this study was to compare the efficacy and safety of jumbo forceps polypectomy (JFP) and cold snare polypectomy (CSP) for the removal of diminutive polyps (DP).

Materials and Methods: Patients who underwent colonoscopy for any reason in our clinic and were found to have DP were randomized into two groups as JFP and CSP. The main outcome was complete polyp resection and complication rate.

Results: A total of 100 polypectomies (50 in each group) were analyzed. The mean age of the patients was $59.1 \pm 11.2$ years. Demographic characteristics of the patients were similar between groups. The overall rate of complete resection for DPs was not significantly different between JFP and CSP groups ( $90 \%$ versus $82 \%, p=0.38$ ). Polypectomy time was significantly longer in the CSP group for polyps $\leq 3 \mathrm{~mm}$ ( $\mathrm{p}=0.008)$. $4 \%$ minor bleeding and $8 \%$ tissue retrieval failure were noted for polyps resected by CSP. The complication rate was significantly higher in the CSP group ( $\mathrm{p}=0.01)$.

Conclusion: JBF and CSP are not statistically different in completely removing DPs. However, the complication rate was lower in the JFP group.

Keywords: Biopsy, colonic polyps, colonoscopy, forceps

\section{Sorumlu Yazar / Corresponding Author:}

Mukaddes Tozlu

Sakarya Üniversitesi Tıp Fakültesi Korucuk eğitim ve Araştırma

Hastanesi

Korucuk/Adapazar1/Türkiye

Tel: 05337711802

E-mail: mukaddestozlu@sakarya.edu.tr
Yayın Bilgisi / Article Info:

Gönderi Tarihi/ Received: 06/12/2021

Kabul Tarihi/ Accepted: 10/01/2022

Online Yayın Tarihi/ Published: 01/03/2022

Atıf / Cited: Tozlu M. Diminutif Poliplerin Endoskopik Tedavisinde Jumbo Forseps ve Soğuk Snare ile Polipektomi Yöntemlerinin Karşılaştırılması. Online Türk Sağlık Bilimleri Dergisi 2022;7(1):93-98. doi: 10.26453/otjhs.1031817 


\section{GíRiş}

Kolon kanseri için malignite potansiyeline sahip poliplerin çoğu kolonoskopi sırasında saptanarak çıkarılabilir. ${ }^{1}$ Kolonoskopi sırasında bulunan poliplerin çoğu (\%75-82) 5 mm'nin altındadır. ${ }^{2} 5 \mathrm{~mm}$ altındaki kolon polipleri diminutif polip (DP) olarak adlandırılmaktadır. ${ }^{3}$

Tüm neoplastik poliplerin tam rezeksiyonu gereklidir. DP'ler sık saptanan polipler olduğundan, bu poliplerin tamamen çıkarılması için uygun polipektomi tekniği seçimi çok önemlidir. Polipektomi teknikleri endoskopistler arasında değişkendir ve endoskopistin tercihine ve yöntemin ulaşılabilirliğine göre belirlenmektedir. ${ }^{4}$

Polipler çeşitli endoskopik tedavi yöntemlerinden biri ile alınabilir. Soğuk forseps polipektomi yöntemi, ulaşılabilirliği, kullanım kolaylığı ve snare ile alınması zor olabilecek küçük poliplerin çıkarılması kolaylığı nedeniyle bazı avantajlara sahiptir. Fakat forseps ile birden fazla 1sırmaya ihtiyaç duyulması ve ilk 1sırıktan sonra kanama ve ödemin polipektomi alanını gizleyerek rezidü kalma riskini artırması dezavantajlarıdır. Yapılan çalışmalarda polipektomi sonrası, tam endoskopik eradikasyondan sonra histolojide \%29 ila \%38 oranında rezidüel adenomatöz doku görülmüştür. ${ }^{5,6}$ Soğuk snare polipektomi (CSP), DP'lerin yönetiminde standart forsepslerden daha etkili görünmektedir. ${ }^{7}$ Jumbo biyopsi forsepsleri (JBF), standart forsepslere kiyasla daha fazla polip dokusu yakalayabilen bir tür soğuk forsepstir.

Son yıllarda standart forsepslere göre daha büyük olan jumbo forsepslerin etkili bir tedavi yöntemi olduğu bildirilse de DP'lerin endoskopik tedavisinde halen fikir birliği yoktur ${ }^{8}$ ve kullanılan yöntemlerin doğrudan karşılaştırmasını içeren az sayıda çalışma yapılmıştır.

$\mathrm{Bu}$ çalışmada DP'lerde, jumbo forseps ve soğuk snare ile yapilan polipektomilerin tam rezeksiyon oranları ve komplikasyonlar yönünden karşılaştırılması amaçlanmıştır.

\section{MATERYAL VE METOT}

Çalışma, Helsinki İlkeleri Bildirgesi'ne uygun olarak gerçekleştirildi ve Sakarya Üniversitesi Tıp Fakültesi, Klinik Araştırmalar Etik Kurulu'ndan onay alındı (Tarih: 17.05.2021, karar no: 117).

Materyaller: Çalışmaya, Mayıs ve Kasım 2021 tarihleri arasında Sakarya Üniversitesi Tıp Fakültesi Gastroenteroloji Kliniği'nde rutin kolonoskopi/ rektosigmoidoskopi (tarama, surveyans veya tanı) uygulanan ve işlem esnasında kolon mukozasında diminutif polip $(\leq 5 \mathrm{~mm})$ saptanan, 18 yaşın üzerindeki hastalar dahil edildi. İşlem öncesi tüm hastalardan yazılı bilgilendirilmiş onam alındı. 18 yaş altı, bilinen koagülopati, inflamatuar bağırsak hastalığı, gebelik, polipozis sendromları olanlar ve kolon te- mizliği yetersiz olanlar dışlandı.

Yöntemler: Hastalar jumbo forseps ve soğuk snare grubu olarak 2 gruba ayrıldı. Hastada polip saptandığında 1:1 randomizasyon ile polipektomi yöntemi seçildi. Bir hastada bir veya daha fazla polip varsa, uygun olan tüm polipler, başlangıçta atanan polipektomi yöntemi kullanılarak çıkarıldı. Polipler boyutlarına göre $\leq 3 \mathrm{~mm}$ ve $4-5 \mathrm{~mm}$ olarak 2 kategoriye ayrıldı. Polipektomiye başlamadan önce polip boyutu standart biyopsi forsepsi kullanılarak ölçüldü. Polipler; Paris sınıflandırmasına göre flat veya sesil olarak sınıflandırıldı. Polipektomi süresi, forseps/snare'in endoskop ucundan çıkışı ile biyopsi örneğinin çıkarılması arasında geçen süre olarak tanımlandi. Yaş, cinsiyet, kolonoskopi endikasyonu, antikoagulan kullanımı, komorbidite, polip boyutu, lokalizasyonu, sayısı, işlem süresi ve diğer demografik bilgiler kaydedildi.

Polipektomi işleminde; CSP grubunda $10 \mathrm{~mm}$ açıklık genişliğine sahip mikro-oval bir snare ve JFP grubunda 8,5 mm ağız açıklığına sahip jumbo forseps kullanıldı. Soğuk snare grubunda; soğuk snare ile polip çevresinde en az $1 \mathrm{~mm}$ normal dokuyu içerecek şekilde alındıktan sonra polipektomi yapıldı. Jumbo forseps grubunda; gerektiği kadar 1sırık ile polip çıkarıldı. Her iki grupta polipektomi bölgesi 30 saniye hemoraji açısından izlendi. Daha sonra serum fizyolojik ile yıkandı ve rezidü açısından endoskopist tarafından değerlendirildi. Rezidü şüphesi olan yerlerden, rezidü şüpheli görünüm yoksa polipektomi bölgesi sağ ve sol kenarlarından tam açılmış standart forseps ile iki adet kontrol biyopsi alındı.

Analizler: Çalışmanın birincil amacı, iki grup arasında tam histolojik polip eradikasyon oranını karşılaştırmaktı. İkincil sonuçlar, polipektomi işlem süresi, doku çıkarma oranı ve polipektomiye bağlı komplikasyon oranları idi. Polipektomi yöntemleri komplikasyon ve polibin komplet/inkomplet çıkarılması açısından karşılaştırıldı.

Ístatistiksel Analiz: Daha önceki çalışmalardaki verilere dayanarak CSP grubu için \%93, jumbo forseps grubu için \%75'lik, tahmini başarı oranlarına dayanarak, $0,05 \alpha$ değerinde ve $\% 80$ güç ile çalışma kolu başına 54 hastalık bir örneklem boyutu belirledik. Kategorik değişkenler, uygun olduğunda $\chi 2$ testi veya Fisher exact testi kullanılarak değerlendirildi. Sürekli değişkenler için Student 's t -testi veya Mann -Whitney U testi kullanıldı. $\mathrm{P}<0,05$ istatistiksel olarak anlamlı kabul edildi. Tüm veriler toplandıktan sonra SPSS 24.0 programı ile uygun istatistiksel yöntemlerle analiz edildi.

\section{BULGULAR}

İki grup arasında başlangıç özelliklerinde anlamlı bir farklılık yoktu Hastaların demografik özellikleri Tablo 1'de görülmektedir.

Toplam 100 polipektomi işlemi (JFP grubu=50 ve 
CSP grubu $=50$ hasta) analiz edildi. Ortalama hasta

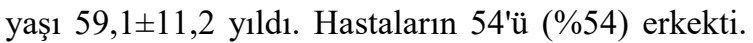
Hastaların demografik özellikleri, komorbiditeleri, kolonoskopi endikasyonu, kolon temizlik skoru, antikoagulan kullanımı her iki grup arasında benzerdi (Tablo 1).

Polip özelliklerine bakıldığında; poliplerin \%62'si $\leq 3 \mathrm{~mm}, \% 38$ 'i 4-5 mm büyüklüğünde idi. Paris sınıflandırmasına göre poliplerin \%59'u sesil, \%41'i flat olarak saptandı. 2 grup arasında polip özellikleri açısından anlamlı fark yoktu (Tablo 2).

Polipektomi yöntemlerinin etkinlik ve güvenilirliğinin karşılaştırılması Tablo 3'de gösterilmiştir.

DP'ler için genel tam rezeksiyon oranı \%86 (86/100) idi. Tam rezeksiyon oranı, JFP ve CSP grupları ara- sında önemli ölçüde farklı değildi (\%90'a karşı \%82, $\mathrm{p}=0,38)$. Rezeke edilen poliplerin histopatolojik incelemesinde $\% 45$ tübüler adenom, $\% 3$ tübülovillöz adenom, $\% 2$ serrated adenom, $\% 36$ hiperplastik, $\% 8$ inflamatuar psödopolip, \%2 karsinom metastazı saptand1. 4 polip, polipektomi sonrası kaybolması nedeniyle patolojik değerlendirme yapılamadı. Polipektomi süresi 2 grup arasında önemli ölçüde farklı değildi $(p=0,28)$. CSP grubunda 2 hastada (\%4) minör kanama izlendi ve 4 polip (\%8) çıkartılamadı. JFP grubunda 1 hastada (\%2) inkomplet rezeksiyon izlendi. Komplikasyon oranı CSP grubunda anlamlı olarak yüksek saptandı ( $\mathrm{p}=0,01)$ (Tablo 3).

Polip boyutlarına göre polipektomi sonuçlarının karş1laştırılması Tablo 4'de gösterilmiştir.

Tablo 1. Hastaların demografik özellikleri.

\begin{tabular}{|l|l|l|l|l|}
\hline & $\begin{array}{l}\text { Toplam } \\
\mathrm{n}=100\end{array}$ & $\begin{array}{l}\text { Jumbo Forseps } \\
\mathrm{n}=50\end{array}$ & $\begin{array}{l}\text { Soğuk Snare } \\
\mathrm{n}=50\end{array}$ & $p$ \\
\hline Yaş (ortalama \pm SS) & $59,1 \pm 11,2$ & $59,2 \pm 11,1$ & $58,9 \pm 11,6$ & 0,93 \\
\hline Erkek cinsiyet, $\mathrm{n}(\%)$ & $54(54)$ & $25(50)$ & $29(58)$ & 0,54 \\
\hline Komorbidite, $\mathrm{n}(\%)$ & $45(45)$ & $23(46)$ & $22(46,8)$ & 1 \\
\hline Kolonoskopi endikasyonu, $\mathrm{n}(\%)$ & $15(15)$ & $7(14)$ & $8(16,3)$ & 0,36 \\
Anemi & $14(14)$ & $6(12)$ & $8(16,3)$ & \\
Karın ağrısı & $7(7)$ & $5(10)$ & $2(4,1)$ & \\
Kabızlık & $52(52)$ & $29(58)$ & $8(46,9)$ & \\
Malignite şüphesi & $11(11)$ & $3(6)$ & $5(10,3)$ & \\
Diğer & $17(17)$ & $12(24)$ & $27(54)$ & 0,1 \\
\hline Antikoagülan kullanımı, $\mathrm{n}(\%)$ & $54(54)$ & $27(54)$ & & 1 \\
\hline Kolon temizlik skoru-İi, $\mathrm{n}(\%)$ & & & \\
\hline
\end{tabular}

SS: Standart sapma.

Tablo 2. Polip özellikleri.

\begin{tabular}{|c|c|c|c|c|}
\hline & $\begin{array}{l}\text { Toplam } \\
\mathrm{n}=100\end{array}$ & $\begin{array}{l}\text { Jumbo Forseps } \\
n=50\end{array}$ & $\begin{array}{l}\text { Soğuk Snare } \\
\mathrm{n}=50\end{array}$ & $p$ \\
\hline $\begin{array}{l}\text { Polip Boyutu, n (\%) } \\
\leq 3 \mathrm{~mm} \\
4-5 \mathrm{~mm}\end{array}$ & $\begin{array}{l}62(62) \\
38(38)\end{array}$ & $\begin{array}{l}31(62) \\
19(38)\end{array}$ & $\begin{array}{l}31(62) \\
19(38)\end{array}$ & 1 \\
\hline $\begin{array}{l}\text { Paris Siniflamas1, n (\%) } \\
\text { Sesil: Ip } \\
\text { Is } \\
\text { Isp } \\
\text { Flat: IIa } \\
\text { IIb }\end{array}$ & $\begin{array}{l}3(3) \\
36(36) \\
20(20) \\
38(38) \\
3(3)\end{array}$ & $\begin{array}{l}2(4) \\
20(40) \\
9(18) \\
18(36) \\
1(2)\end{array}$ & $\begin{array}{l}1(2) \\
16(32) \\
11(22) \\
20(40) \\
2(4)\end{array}$ & 0,83 \\
\hline $\begin{array}{l}\text { Polip Lokalizasyonu, n (\%) } \\
\text { Rektum } \\
\text { Sigmoid } \\
\text { İnen kolon } \\
\text { Transvers kolon } \\
\text { Ç1kan kolon ve çekum }\end{array}$ & $\begin{array}{l}22(22) \\
34(34) \\
14(14) \\
18(18) \\
11(11)\end{array}$ & $\begin{array}{l}11(22) \\
15(30) \\
8(16) \\
10(20) \\
5(10)\end{array}$ & $\begin{array}{l}11(22) \\
19(38) \\
6(12) \\
8(16) \\
6(12)\end{array}$ & 0,95 \\
\hline
\end{tabular}




\section{TARTIŞMA VE SONUÇ}

Kolorektal poliplerin erken tanı ve tedavisine yardımcı olan kolonoskopi ve polipektomi işlemleri, kolorektal kanser riskini azaltan önemli minimal invaziv işlemlerdir. Kolonoskopi sırasında bulunan poliplerin çoğu DP'dir ve DP'lerin \%50 ila \% 64'ünün adenom olduğu bildirilmektedir. ${ }^{9}$ DP'ler malign potansiyelleri nedeniyle tamamen rezeke edilmelidir. Daha önceki çalışmalarda, 5 ila $20 \mathrm{~mm}$ arasındaki polipler için yaklaşık \%10'luk tam olmayan rezeksiyon oranları rapor edilmiştir. ${ }^{10} \mathrm{Bu}$ nedenle tam rezeksiyon oranını iyileştirmek için polipektomi tekniklerinin standardizasyonuna ihtiyaç vardir.

Standart forseps, sicak ve jumbo biyopsi forsepsi, soğuk snare ve sıcak snare gibi çeşitli polipektomi yöntemleri vardır. DP'lerde sıcak yöntemlerde koter artefaktı nedeniyle histopatolojik değerlendirme zorluğu ve gecikmiş kanama ile karşılaşılabileceği bildirilmiştir. ${ }^{11}$ Standart forseps, jumbo forseps, soğuk snare polipektomi gibi soğuk yöntemlerde bu risklere nadiren rastlanır. Standart biyopsi forsepsleri (SBF), kullanım kolaylığg ve güvenliği nedeniyle DP'lerin çıkarılmasında tercih edilmiştir. Ancak çalışmalarda, SBF'nin tam olmayan polipektomi oranı $\% 29$ ile $\% 61$ arasında rapor edilmiştir ${ }^{6}$ ve özellikle $>3 \mathrm{~mm}$ poliplerde tam rezeksiyon oranlar1nın, CSP ve JFP'den daha düşük olduğu bildirilmiştir. ${ }^{12,13}$ DP'lerin çıkarılmasında JFP'nin etkinliği konusunda tartışmalar mevcuttur. Bir meta-analiz, JFP'nin toplam işlem süresini artırmadan yetersiz polip rezeksiyon oranlarını $\% 60$ oranında azaltabildiğini bildirmiştir. ${ }^{14}$ SBF ile karşılaştırıldığında, jumbo forsepsin daha az isırma ile tam rezeksiyon sağlayabilen daha geniş bir ağız açıklığı vardır.

DP'lerin tedavisinde bir diğer tedavi seçeneği de CSP yöntemidir. CSP, polip tabanının etrafındaki 2$3 \mathrm{~mm}$ normal mukozanın yakalanması gibi teknik bir avantaja sahiptir. Bu da daha yüksek en-blok tam

Tablo 3. Polipektomi yöntemler inin etkinlik ve güvenilir liğinin karşılaştırılması.

\begin{tabular}{|c|c|c|c|c|}
\hline & $\begin{array}{l}\text { Toplam } \\
\mathrm{n}=100\end{array}$ & $\begin{array}{l}\text { Jumbo Forseps } \\
n=50\end{array}$ & $\begin{array}{l}\text { Soğuk Snare } \\
n=50\end{array}$ & $p$ \\
\hline Tam rezeksiyon & $86(86)$ & $45(90)$ & $41(82)$ & 0,38 \\
\hline Rezidü var, n(\%) & $14(14)$ & $5(10)$ & $9(18)$ & 0,38 \\
\hline $\begin{array}{l}\text { Polipektomi süresi, sn } \\
\text { (ortalama } \pm \text { SS) }\end{array}$ & $55,4 \pm 46,2$ & $53,8 \pm 48,9$ & $57,1 \pm 43,6$ & 0,28 \\
\hline $\begin{array}{l}\text { Polip patoloji, n(\%) } \\
\text { Hiperplastik } \\
\text { Tubuler adenom } \\
\text { Tubulovillöz adenom } \\
\text { Yok-kayıp } \\
\text { İnflamatuvar } \\
\text { Serrated } \\
\text { Karsinom metastazı }\end{array}$ & $\begin{array}{l}36(36) \\
45(45) \\
3(3) \\
4(4) \\
8(8) \\
2(2) \\
2(2)\end{array}$ & $\begin{array}{l}19(38) \\
24(48) \\
1(2) \\
- \\
4(8) \\
- \\
2(4)\end{array}$ & $\begin{array}{l}17(34) \\
21(42) \\
2(4) \\
4(8) \\
4(8) \\
2(4) \\
-\end{array}$ & 0,1 \\
\hline $\begin{array}{l}\text { Komplikasyon, } \mathrm{n}(\%) \\
\text { Yok } \\
\text { Kanama } \\
\text { Polip bulunamadı } \\
\text { İnkomplet rezeksiyon }\end{array}$ & $\begin{array}{l}93(93) \\
2(2) \\
4(4) \\
1(1) \\
\end{array}$ & $\begin{array}{l}49(98) \\
- \\
- \\
1(2) \\
\end{array}$ & $\begin{array}{l}44(88) \\
2(4) \\
4(8) \\
-\end{array}$ & 0,01 \\
\hline
\end{tabular}

SS: Standart sapma.

Tablo 4. Polip boyutlarına göre polipektomi sonuçlarının karşılaştırılması.

\begin{tabular}{|c|c|c|c|c|c|}
\hline$\leq \mathbf{3 m m}$ & & $\begin{array}{l}\text { Toplam } \\
\mathrm{n}=62\end{array}$ & $\begin{array}{l}\text { Jumbo Forseps } \\
\mathbf{n}=\mathbf{3 1}\end{array}$ & $\begin{array}{l}\text { Soğuk Snare } \\
\mathbf{n}=\mathbf{3 1}\end{array}$ & $p$ \\
\hline $\begin{array}{ll}\begin{array}{l}\text { Polipektomi } \\
(\text { ortalama } \pm S S)\end{array} & \text { süresi, }\end{array}$ & & $48,6 \pm 37,8$ & $37,1 \pm 28,1$ & $60,6 \pm 43,1$ & $\overline{0,008}$ \\
\hline Rezidü, n (\%) & & $8(12,9)$ & $2(6,5)$ & $6(19,4)$ & 0,25 \\
\hline $4-5 \mathrm{~mm}$ & & $\begin{array}{l}\text { Toplam } \\
n=38\end{array}$ & $\begin{array}{l}\text { Jumbo Forseps } \\
n=19\end{array}$ & $\begin{array}{l}\text { Cold Snare } \\
n=19\end{array}$ & $p$ \\
\hline $\begin{array}{l}\text { Polipektomi } \\
(\text { ortalama } \pm \text { SS })\end{array}$ süresi, & & $66,9 \pm 56,4$ & $81,2 \pm 62,6$ & $50,8 \pm 45,2$ & 0,14 \\
\hline Rezidü, n (\%) & & $6(30,8)$ & $3(15,8)$ & $3(15,8)$ & 0,34 \\
\hline
\end{tabular}

SS: Standart sapma. 
rezeksiyon sağlar. Bu tekniğin ana dezavantajı, polipektomiden sonra polip çıkarmanın başarısız olabilmesidir. Özellikle doku gayta ve kan ile karıştığında, çıkarılan polip bazen aspire edilmeden önce kolonda kaybolabilir. ${ }^{15,16}$

JFP ile CSP yöntemlerinin rezeksiyon oranlarını doğrudan karşılaştıran az sayıda çalışma vardır. DP'lerin çıkarılması için CSP'yi öneren son kılavuzlara rağmen, endoskopistler arasında soğuk forseps polipektomisi tercih edilen teknik olmaya devam etmektedir. ${ }^{17,18} \mathrm{Bu}$ muhtemelen birkaç faktörden kaynaklanmaktadır. Soğuk forseps hemen tüm endoskopi ünitelerinde mevcuttur, kullanımı kolaydır ve snare polipektomiye kiyasla endoskopist ve asistan arasında daha az koordinasyon gerektirir. Ek olarak, forseps, polipin küçük boyutu veya konumu nedeniyle, snare ile yakalanması zor olabilecek polipleri kolayca kavrayabilir. Ayrıca, snare polipektominin aksine, forseps ile elde edilen doku örneğinin kaybolma olasılığı daha düşüktür ve hemen alınabilir. Fakat biyopsi ile yüksek tam olmayan histolojik rezeksiyon oranı önemli bir endişe kaynağıdır. ${ }^{5,13}$

$\mathrm{Bu}$ nedenle, bu çalışmada diminutif polipektominin etkinliği ve güvenliği açısından CSP ile JFP'yi doğrudan karşılaştıran bir randomize kontrollü çalışma yaptık.

Çalışmamızda tüm DP'lerin >\%90'ı JFP veya \% 82'si CSP ile tamamen rezeke edildi. CSP grubunun doku çıkarma oranı, JFP grubuna göre daha düşüktü, ancak istatistiksel olarak anlamlı değildi $(\mathrm{p}=0,38)$. Tüm polipler değerlendirildiğinde iki grup arasında polipektomi süresi açısından anlamlı bir fark yoktu. Polip boyutlarına göre yapılan analizde, $\leq 3 \mathrm{~mm}$ poliplerde toplam rezidü oran $1 \% 12,9$ ve $4-5 \mathrm{~mm}$ boyutunda polipler için toplam rezidü oranı $\% 30,8$ olarak saptand 1 ve gruplar arasında anlamlı farklılık izlenmedi. $\leq 3 \mathrm{~mm}$ poliplerde polipektomi süresi JFP grubunda anlamlı olarak daha kısaydı $(\mathrm{p}=0,008)$. 4-5 $\mathrm{mm}$ polipler için polipektomi süresi JFP grubunda daha yüksek saptanmasına rağmen gruplar arasında farklılık göstermedi $(\mathrm{p}=0,14)$.

Çalışmalarda CSP tekniği ile küçük ama önemli sayıda doku alma başarısızlığı bildirilmiştir, bu da gereksiz polipektomi sonrası sürveyansa yol açabilir. ${ }^{16,19}$ Yine, soğuk snare veya biyopsi sonrası minör kendi kendini sınırlayan mukozal kanama olabilir. CSP, diğer yöntemlerle karşılaştırıldığında, özellikle polipektomi sonrası kanama gibi yan etkilerle ilişkilendirilmiştir. Bizim çalışmamızda; CSP grubunda 2 hastada (\%4) minör kanama izlendi ve 4 polip (\%8) çıkartılamadı. JFP grubunda 1 hastada (\%2) inkomplet rezeksiyon izlendi. Komplikasyon oran 1 CSP grubunda anlamlı olarak yüksek saptandı $(p=0,01)$. Sonuçlarımıza göre, DP'lerin polipektomisinde, JFP yöntemi polipektomi materyalinin kolonda kaybolmadan forseps içinde çıkarılması için kolay ve etkili bir endoskopik tedavi seçeneği olarak düşünülebilir.

$\mathrm{Bu}$ çalışmanın çeşitli kısıtlılıkları vardır. Birincisi, polipektomiyi yapan kolonoskopistin rezeksiyon yöntemine kör olmamasıdır. Bu, biasa neden olmuş olabilir. Bununla birlikte, yöntemlerin belirgin görünümü nedeniyle böyle bir körleme muhtemelen imkansızdır. İkincisi, polipektomi bölgesinden alınan iki ek biyopsi örneği rezidü dokuları tespit etmek için yetersiz olabilir. Narrow band imaging (NBI) veya chromoendoscopy ile polipektomi bölgesinin değerlendirilmesi rezidü dokuların tespit edilmesine katkıda bulunabilir. Son olarak, çalışmamız nispeten küçük bir örneklem büyüklüğüne sahipti.

Sonuç olarak; $\leq 5 \mathrm{~mm}$ kolorektal poliplerin eksizyonunda JFP ve CSP güvenilir yöntemlerdir. Rezidü açısından bu iki yöntemin birbirlerine üstünlük sağladıkları gösterilmemişse de, JFP yöntemi ile komplikasyon oranları daha düşük saptanmıştır. DP'lerin çıkarılması için forseps düşünülürse, bu çalışmanın sonuçlarına göre JFP önerilebilir. Polipektomi yöntemlerinden bağımsız olarak soğuk polipektomi sonrası rezidü polip riski devam ettiği için, polipektomi bölgesinin detaylı incelenmesi gerekmektedir.

Etik Komite Onayı: Sakarya Üniversitesi Klinik Araştırmalar Etik Kurulu (Tarih: 17.05.2021 karar no: 117). Çalışma uluslararası deklarasyon, ve kılavuzlara uygun gerçekleştirilmiştir.

Çıkar Çatışması: Yazarlar çıkar çatışması bildirmemişlerdir.

Yazar Katkıları: Fikir - MT; Denetleme- MT; Malzemeler - MT; Veri toplanması ve/veya işlemesi - MT; Analiz ve/veya yorum - MT; Yazıyı yazan - MT.

Hakem Değerlendirmesi: Diş bağımsız.

\section{KAYNAKLAR}

1. Zauber AG, Winawer SJ, O'Brien MJ, ve ark. Colonoscopic polypectomy and long-term prevention of colorectal-cancer deaths. $\mathrm{N}$ Engl J Med. 2012;366(8):687-696. doi:10.1056/ NEJMoa 1100370

2. Huh CW, Kim JS, Choi HH, Maeng IS, Jun SY, Kim BW. Jumbo biopsy forceps versus cold snares for removing diminutive colorectal polyps: a prospective randomized controlled trial. Gastrointest Endosc. 2019;90(1):105-111. doi:10.1016/ j.gie.2019.01.016

3. Anderloni A, Jovani M, Hassan C, Repici A. Advances, problems, and complications of polypectomy. Clin Exp Gastroenterol. 2014;7:285-296. doi:10.2147/CEG.S43084

4. Pedersen IB, Loberg M, Hoff G, Kalager M, Bretthauer M, Holme O. Polypectomy techniques among gastroenterologists in Norway - a nationwide survey. Endosc Int Open. 2018;6 
(7):E812-E820. doi:10.1055/a-0607-0727

5. Liu S, Ho SB, Krinsky ML. Quality of polyp resection during colonoscopy: are we achieving polyp clearance? Dig Dis Sci. 2012;57(7):17861791. doi:10.1007/s10620-012-2115-6

6. Efthymiou M, Taylor AC, Desmond PV, Allen $\mathrm{PB}$, Chen RY. Biopsy forceps is inadequate for the resection of diminutive polyps. Endoscopy. 2011;43(4):312-316. doi:10.1055/s-00301256086

7. Lee CK, Shim JJ, Jang JY. Cold snare polypectomy vs. Cold forceps polypectomy using doublebiopsy technique for removal of diminutive colorectal polyps: a prospective randomized study. Am J Gastroenterol. 2013;108(10):1593-1600. doi:10.1038/ajg.2013.302

8. Draganov PV, Chang MN, Alkhasawneh A, ve ark. Randomized, controlled trial of standard, large-capacity versus jumbo biopsy forceps for polypectomy of small, sessile, colorectal polyps. Gastrointest Endosc. 2012;75(1):118-126. doi:10.1016/j.gie.2011.08.019

9. Tsai FC, Strum WB. Prevalence of advanced adenomas in small and diminutive colon polyps using direct measurement of size. Dig Dis Sci. 2011;56(8):2384-2388. doi:10.1007/s10620-0111598-x

10. Pohl H, Srivastava A, Bensen SP, ve ark. Incomplete polyp resection during colonoscopy-results of the complete adenoma resection (CARE) study. Gastroenterology. 2013;144(1):74-80.e1. doi:10.1053/j.gastro.2012.09.043

11. Mönkemüller KE, Fry LC, Jones BH, Wells C, Mikolaenko I, Eloubeidi M. Histological quality of polyps resected using the cold versus hot biopsy technique. Endoscopy. 2004;36(5):432-436. doi:10.1055/s-2004-814321

12. Kim JS, Lee BI, Choi H, ve ark. Cold snare polypectomy versus cold forceps polypectomy for diminutive and small colorectal polyps: a randomized controlled trial. Gastrointest Endosc. 2015;81(3):741-747.

doi:10.1016/ j.gie.2014.11.048

13. Park SK, Ko BM, Han JP, Hong SJ, Lee MS. A prospective randomized comparative study of cold forceps polypectomy by using narrow-band imaging endoscopy versus cold snare polypectomy in patients with diminutive colorectal polyps. Gastrointest Endosc. 2016;83(3):527-532. doi:10.1016/j.gie.2015.08.053

14. Raad D, Tripathi P, Cooper G, Falck-Ytter Y. Role of the cold biopsy technique in diminutive and small colonic polyp removal: a systematic review and meta-analysis. Gastrointest Endosc. 2016;83(3):508-515. doi:10.1016/ j.gie. 2015.10 .038

15. Deenadayalu VP, Rex DK. Colon polyp retrieval after cold snaring. Gastrointest Endosc. 2005;62 (2):253-256. doi: 10.1016/s0016-5107(05)003767

16. Komeda Y, Suzuki N, Sarah M, ve ark. Factors associated with failed polyp retrieval at screening colonoscopy. Gastrointest Endosc. 2013;77 (3):395-400. doi:10.1016/j.gie.2012.10.007

17. Fyock CJ, Draganov PV. Colonoscopic polypectomy and associated techniques. World J Gastroenterol. 2010;16(29):3630-3637. doi:10.3748/ wjg.v16.i29.3630

18. Jung YS, Park CH, Nam E, Eun CS, Park DI, Han DS. Comparative efficacy of cold polypectomy techniques for diminutive colorectal polyps: a systematic review and network meta-analysis. Surg Endosc. 2018;32(3):1149-1159. doi:10.1007/s00464-017-5786-4

19. Ichise Y, Horiuchi A, Nakayama Y, Tanaka N. Prospective randomized comparison of cold snare polypectomy and conventional polypectomy for small colorectal polyps. Digestion. 2011;84(1):78 -81. doi:10.1159/000323959 